Macromolecular Nanotechnology

\title{
Rigid polyurethane foams with infused nanoclays: Relationship between cellular structure and thermal conductivity
}

\author{
Sergio Estravís a , Josías Tirado-Mediavilla a , Mercedes Santiago-Calvo a , José Luis Ruiz-Herrero ${ }^{a}$, \\ Fernando Villafañe ${ }^{\mathrm{b}}$, Miguel Ángel Rodríguez-Pérez ${ }^{\mathrm{a}, *}$ \\ ${ }^{a}$ Cellular Materials Laboratory (CellMat), Condensed Matter Physics Department, Science Faculty, University of Valladolid, Paseo de Belén, 7, 47011 Valladolid, Spain \\ ${ }^{\mathrm{b}}$ GIR MIOMeT-IU Cinquima-Química Inorgánica, Science Faculty, University of Valladolid, Paseo de Belén, 7, 47011 Valladolid, Spain
}

\section{A R T I C L E I N F O}

\section{Article history:}

Received 29 September 2015

Received in revised form 29 March 2016

Accepted 21 April 2016

Available online 22 April 2016

\section{Keywords:}

Polyurethane foam

Thermal conductivity

Cellular nanocomposites

Nanoclays

\begin{abstract}
A B S T R A C T
A water blown rigid polyurethane (PU) formulation has been used to manufacture cellular nanocomposites containing different concentrations of montmorillonite nanoclays. The PU foams have been produced using a low shear mixing technique for dispersing the nanoclays and by reactive foaming to generate the cellular structure. A detailed characterization of the cellular structure has been performed. The effect of the nanoparticles on the reaction kinetics and the state of intercalation of the nanoparticles in the foams has been analyzed. The thermal conductivity and extinction coefficient of the different materials has been measured and the results obtained have been correlated with the materials structure. A strong reduction of cell size and modifications on cell size distribution, anisotropy ratio and fraction of material in the struts has been detected when the clays are added. In addition, a reduction of the thermal conductivity has been observed. Different theoretical models have been employed to explain thermal conductivity changes in terms of structural features. It has been found that, in addition to the modifications in the cellular structure, changes in the extinction coefficient and thermal conductivity of the matrix polymer play an important role on the final values of the thermal conductivity for these materials.
\end{abstract}

(c) 2016 Elsevier Ltd. All rights reserved.

\section{Introduction}

Thermal insulation is indeed one of the major concerns in the development of heat transfer technology. The aim of thermal insulation is to reduce heat transfer between a medium and its environment, so that the system temperature can be maintained at a fixed value with minimum energy consumption for a large period of time. Even small reductions, in relative terms, of thermal conductivities will involve, with time, large reductions in terms of energy employed. Among insulating materials, such as powders, fibrous boards, multilayer systems, or vacuum panels, closed cell polymeric foams present several advantages, as their low-cost and their easy production and maintenance [1]. For these reasons, polymeric foams are the most widely used thermal insulators both in construction and engineering applications.

Polyurethane (PU), based on the reaction of isocyanate and polyol, is one of the most versatile materials in foam's world, with a wide range of applications in different industries such as building, automotive, sports, naval and furniture. In partic-

\footnotetext{
* Corresponding author.

E-mail address: marrod@fmc.uva.es (M.A. Rodríguez-Pérez).
} 
ular, rigid polyurethane (PUR) foams are the most popular foam insulators due to their low thermal conductivity, high strength-to-weight ratio and low cost [2-5].

On the other hand, nanoparticles play nowadays a fundamental place in cellular polymers research [6-9]. Their role is fundamentally based on two different aspects: the cellular structure could be modified and the properties of the solid matrix can be improved if there is a good nanoparticle-matrix interaction [10-12]. Thus, some properties of the foams, such as stiffness, strength and thermal insulation [13-15], can be improved, or new properties, like electrical conductivity [6] may emerge by the addition of nanoparticles. However, only the addition of nanofillers does not guarantee optimal results [16], and it also required a good distribution and dispersion [17], as well as strong interactions between the nanofillers and the polymeric matrix [18].

As the rest of polymeric foams, polyurethane is susceptible to improve its properties by addition of nanoparticles, and a wide range of them have been used for this purpose: Saha et al. [14] investigated the effects of different types of nanoparticles $(1 \mathrm{wt} \%)$ on the thermal and mechanical performance of rigid polyurethane (PUR) foams; they found significant enhancement in several properties; Kabir et al. [19] studied the effects of different sonication parameters on the mechanical properties of rigid PU foams infused with carbon nanofibers (CNFs), obtaining that sonication has an optimum time window which depends on sonicator power and nanoparticles concentration. Mahfuz et al. [20] produced foam panels containing different types of ultrasonicated nanoparticles obtaining an optimal dispersion and observing a significant increase (ca. 5070\%) of flexural strength and stiffness. Modesti et al. [15] studied flame retardancy synergies by using both aluminum phosphinate, as phosphorus-based flame retardant, and layered silicates in polyurethane foams, obtaining that clays act as physical barriers at the surface, which prevent or slow down the diffusion of volatiles and oxygen, while phosphinate is more effective owing to its combined action in both condensed and gas phases. Cao et al. [16] studied the processing, structure and properties of polyurethane-clay nanocomposites foams, both rigid and flexible, observing a cell density increase and a cell size reduction for nanocomposites compared to pure $\mathrm{PU}$ foam. They also observed a reduction of $\mathrm{T}_{\mathrm{g}}$ and of the mechanical properties of rigid foams. Widya and Macosko [21] incorporated different montmorillonite based organoclay concentrations (1, 2, 3 and $5 \mathrm{wt} \%$ ) into rigid polyurethane foams using ultrasounds to disperse the particles. They obtained a cell size reduction and cell density increase even for the lowest nanoclays concentration.

The variation of the thermal conductivity due to the inclusion of nanoclays has also been previously studied in rigid polyurethane foams. Modesti et al. [22] studied the effect of different nanofillers (diverse types of nanoclays, titanium dioxide and silica nanopowder) on the thermal insulating properties [22]. Fillers were first dispersed in the polyol component by sonication, achieving a good degree of dispersion, and a slight reduction of the thermal conductivity. The authors reported that in some cases the fillers could increase the open cell content, accelerating the diffusion rate of the blowing agents what might result in worse thermal insulating properties at long times. The high number of formulation-nanoparticles used in this paper did not allow to deeply studying their effect on the final properties of the foam.

Harikrishnan et al. [23] also studied the nanoclays effect on the thermal properties of rigid polyurethane foams. In this publication, rigid and flexible foams infused with nanoclays were studied. They concluded that clays act as efficient cell openers in both in rigid and flexible foams and that the fraction of open cells increases when increasing clay concentration. Modified clays were found to be more efficient cell openers than the unmodified clay, and thermal conductivity of the rigid foams was not significantly affected by clay addition. The use of modified clays was able to reduce significantly the cell size [22,24]. As in the previous paper, the large variety of samples used prevented for a detailed study on the structure-property relationships.

This paper is focused on studying the effect of nanoclays on the foam structure and on the thermal conductivity of a rigid polyurethane system using a different approach. The articles above were focused on a wide range of nanometric particles, using diverse polyurethane formulations, what precluded a detailed study of each particular system. The aims of the present work are to obtain a complete characterization of the different heat transfer mechanisms involved in the thermal conductivity, analyzing the effect of the nanoparticles inclusion on these heat transfer mechanisms and to study of the structure-property relationships. For this reason, we have selected only a particular formulation and a specific type of functionalizated nanoclays, with the main target of obtaining an exhaustive understanding of this particular system. The evolution of thermal conductivity with time has been studied, and a complete morphological characterization, with special attention to the cellular structure, has been performed. The latter is an important aspect which had not been profoundly studied in previous studies, and which is subjected to important changes by the presence of nanoparticles. The experimental data obtained from the characterization, supported by different theoretical models, has permitted identifying both the origin of the changes in the final thermal conductivity of the foam and the effect of nanoclays on the different heat transfer mechanisms.

\section{Materials and methods}

\subsection{Materials}

A commercial, bi-component formulation of rigid polyurethane foam, supplied by BASF was used in this research. This formulation is based on methylene diphenyl diisocyanate (MDI) and a mixture of polyether polyol, catalysts, additives and blowing agent (water). The main characteristics of this formulation are collected in Table 1. 
Table 1

Main properties of the rigid PU formulation used in this paper.

\begin{tabular}{ll}
\hline Density $\left(\mathrm{kg} / \mathrm{m}^{3}\right.$, free foaming) & $52 \pm 5$ \\
Polyol/isocyanate ratio & $100 / 160$ \\
$\mathrm{NCO}$ content $(\%)$ & 31.5 \\
OH index $(\mathrm{mg}$ of $\mathrm{KOH} / \mathrm{g}$ polyol) & 651 \\
Polyol viscosity $(\mathrm{mPa} \cdot \mathrm{s})$ & 650 \\
Gel time (s) & $145 \pm 15$
\end{tabular}

Cloisite 30B nanoclay is a natural montmorillonite modified with a quaternary ammonium salt, purchased from Southern Clay Products $[25,26]$. These nanoclays are commonly employed to improve different physical properties of polymers, such as stiffness, strength, heat distortion temperature, linear thermal expansion coefficient, and barrier features [18]. The concentration of nanoclays included in the different samples was $0.5,1,3$ and $5 \mathrm{wt} \%$.

The technique employed for nanoclays dispersion was low-shear mixing. The procedure to obtain nanocomposite foams was as follows: firstly the nanoclays were dried under vacuum for $12 \mathrm{~h}$ at $40^{\circ} \mathrm{C}$, to remove any trace of moisture. Then nanoclays were premixed with polyol in a plastic container, using an IKA Eurostar Power control-visc P1, equipped with an Xshaped blade, at $200 \mathrm{rpm}$ for $120 \mathrm{~s}$. Then a precise amount of isocyanate (Table 1) was added and mixed at $1200 \mathrm{rpm}$ for $15 \mathrm{~s}$ with the shame mixer equipped with a Lenart Disc. The mixed liquids were poured for foaming into a mold with dimensions $310 \times 250 \times 60 \mathrm{~mm}^{3}$. The nominal density expected was $52 \pm 5 \mathrm{~kg} / \mathrm{m}^{3}$.

After the foaming and curing process (at least $48 \mathrm{~h}$ at room temperature), samples were cut from the produced block to characterize them. Thermal conductivity measurements were performed on square samples of $100 \mathrm{~mm}$ side and $20 \mathrm{~mm}$ in thickness obtained from the center of the blocks. The remaining block was machined into different shapes to carry out the rest of measurements. Samples close to the mold walls were not used to avoid possible heterogeneities (higher densities) in these areas.

\subsection{Characterization}

Foamed samples were conditioned at $24{ }^{\circ} \mathrm{C}$ and $50 \%$ relative humidity for at least $48 \mathrm{~h}$ and subjected to density measurements in accordance with ASTM D1622.

Quantitative image analysis was used to measure the cell size variation of the different samples. For this purpose, cured foams were cut to provide a smooth surface, which, after vacuum coating with gold, was examined by Scanning Electron Microscopy (SEM) using a JEOL JSM 820 equipment. A specific plug-in developed for Image [27] was employed for cell size quantification, and at least 100 cells were measured in each material. Cell size distribution, average cell size and anisotropy ratio (AR) (ratio between the cell size in the growing direction and the average cell size in the perpendicular plane to the growing direction) were measured. The width of the cell size distribution was also calculated using the normalized standard deviation (NSD):

$$
N S D=\frac{\left(\sum_{i}\left(m_{i}-\sum_{i} m_{i} f_{i}\right)^{2} f_{i}\right)^{1 / 2}}{\sum_{i} m_{i} f_{i}}
$$

where $n_{i}$ represents the number of cells with a size between $a_{i}$ and $b_{i}, n$ is the total number of analyzed cells, $m_{i}=\left(a_{i}+b_{i}\right) / 2$ and $f_{i}=n_{i} / n$.

Open-cell measurements were performed with an air pycnometer (Eijkelcamp 08.06 Langer) in cubic samples with lateral dimensions of $30 \mathrm{~mm}$. A correction due to cells cut present in the samples surface was made in accordance with ASTM D2856.

The fraction of mass in the struts $\left(\mathrm{f}_{\mathrm{s}}\right)$ was measured using micro-tomography images by an image analysis procedure published elsewhere [28].

In order to determine the pure nanoclays interplanar distance and its variation when nanoclays were mixed with polyol or infused in the polyurethane foam, X-ray diffraction experiments were performed using a X-ray equipment Bruker discover D8 (equipped with LynxEye detector) in a Bragg-Brentano geometry, employing a CuKa as X-ray generator. A voltage of $40 \mathrm{KV}$ and $30 \mathrm{~mA}$ of current were used in all experiments. Studied angles varied from $0.5^{\circ}$ to $10^{\circ}$. These experiments were performed to obtain information about the intercalation state of the nanoparticles in the blends polyol-nanoclays, isocyanate-clays and in the resulting foam. The mixing condition for the polyol-nanoclays and for isocyanate-nanoclays was the same as the ones presented in Section 2.

To characterize the reaction kinetics and in particular the blowing to gelling ratio in the evolving PU system, FTIR studies were carried out during the foaming process. FTIR spectra of the samples were collected using a Bruker Tensor 27 spectrometer by transmission method using $\mathrm{NaCl}$ plates. The spectra were obtained after 16 scans with a resolution of $4 \mathrm{~cm}^{-1}$ over a wavenumbers range of $4000-500 \mathrm{~cm}^{-1}$ under a $\mathrm{N}_{2}$ purge. A background spectrum was subtracted from each reaction spectra. 45 spectra were run for each experiment, which lasted $16 \mathrm{~min}$. The asymmetric $\mathrm{CH}$ stretching band at $2972 \mathrm{~cm}^{-1}$ was 
used as internal reference band to normalize the spectra, since its concentration remains constant during the reaction. Moreover, a baseline correction was conducted to correct the shifts from temperature changes in each spectrum.

The extinction coefficient of the final foams was measured using the same FTIR equipment. These experiments were performed with 5 thin samples cut from the foams, where the thickness (L) range was between 0.5 and $2.5 \mathrm{~mm}$. The sample diameter and beam diameter were 12 and $1.5 \mathrm{~mm}$, respectively. Transmittance spectra were taken for samples of various thicknesses. The transmittance $\left(\tau_{n, \lambda}\right)$ is the ratio of the intensity transmitted through the sample $\left[I_{\lambda}(x)\right]$ to the intensity without the sample $\left[I_{0, \lambda}\right]$ :

$$
\tau_{n, \lambda}=\frac{I_{\lambda}(x)}{I_{0, \lambda}}
$$

Transmission measurements were performed in the wavenumber infrared region from 4000 to $400 \mathrm{~cm}^{-1}$. The data supplied by the software were a collection of 1865 values in this range. The spectral extinction coefficient $\left(K_{e, \lambda}\right)$ for thin samples can be obtained from Beer's law [1]. For homogeneous samples, once $K_{e, \lambda}$ is assumed to be independent of sample thickness, the following expressions are valid:

$$
\tau_{n, \lambda}=e^{\left(-\int_{0}^{L} K_{e, \lambda} d x\right)}
$$

where

$$
K_{e, \lambda}=\frac{-\ln \left(\tau_{n, \lambda}\right)}{L}
$$

Thus, $K_{e, \lambda}$ can be obtained by means of a linear regression $\left(\operatorname{Ln}\left(\tau_{e, \lambda}\right) v s . L\right)$.

A Rapid K Heat Flow Meter from Holometrix was used for thermal measurements. Heat flow through the test sample (q) results from having a temperature gradient $(\Delta \mathrm{T})$ across the material. The thermal conductivity $\lambda$ is defined according to Fourier's equation:

$$
q=\lambda A \frac{\Delta T}{d}
$$

where $A$ is the cross-sectional area of the sample and $d$ is the sample thickness.

Measurements were performed under steady state heat flow conditions through the test sample in accordance with UNE12667 method. A dispersion of less than $1 \%$ in two consecutive readings was taken as a criterion to ensure that the measurements were done under steady state conditions. The time lap between readings was 10 min. Except some measurements carried out to evaluate the evolution of thermal conductivity with time, the rest of measurements were performed 12 days after foams production, with the aim that all $\mathrm{CO}_{2}$ created during foaming had diffused out to atmosphere and only air is inside the foams. The measurements were performed at $20^{\circ} \mathrm{C}$. Each experiment was repeated 5 times in order to obtain an average value of the thermal conductivity.

\section{Results}

\subsection{Structural characterization}

Density of the foams is shown in Table 2. In general terms, the macroscopic density tends to increase when nanoclays are added. The reason for this slight growth could be related to the higher viscosity of the initial blend when clays are infused $[29,30]$. Nevertheless, these changes in density (4\% in the sample containing $5 \%$ nanoclays) can be considered small, taking into account that polyurethane foam density is very sensitive to small changes in environmental conditions, like moisture and temperature, and to small changes in mixing times [31].

Fig. 1 shows a typical SEM image of the cellular structure of the materials under study (PU foam containing $3 \%$ clays). The foam shows a homogeneous closed cell structure with cells slightly oriented in the growing direction.

Analysis of SEM images also provides quantitative information about the cell size distribution in a plane containing the growing direction, the average cell size (Figs. 2 and 3 respectively) and other parameters characteristics of the cellular structure (Table 2).

Table 2

Density and cell features of the manufactured materials.

\begin{tabular}{llllll}
\hline Sample (nanoclays concentration wt\%) & Density $\left(\mathrm{kg} / \mathrm{m}^{3}\right)$ & $\mathrm{NSD}$ & $\mathrm{f}_{\mathrm{s}}$ & Anisotropy ratio (AR) (x/y) & Open cell content (\%) \\
\hline 0 & $53.10 \pm 0.21$ & $0.20 \pm 0.019$ & $0.67 \pm 0.02$ & $1.69 \pm 0.17$ & $6.65 \pm 1.10$ \\
0.5 & $52.58 \pm 0.85$ & $0.19 \pm 0.018$ & $0.62 \pm 0.03$ & $1.31 \pm 0.14$ & $6.50 \pm 0.38$ \\
1 & $54.07 \pm 0.93$ & $0.36 \pm 0.038$ & $0.66 \pm 0.04$ & $1.12 \pm 0.10$ & $8.24 \pm 0.93$ \\
3 & $55.50 \pm 0.30$ & $0.35 \pm 0.032$ & $0.78 \pm 0.03$ & $1.40 \pm 0.15$ & $8.52 \pm 0.74$ \\
5 & $55.38 \pm 0.62$ & $0.62 \pm 0.061$ & $0.76 \pm 0.02$ & $1.04 \pm 0.09$ & $8.30 \pm 0.71$ \\
\hline
\end{tabular}




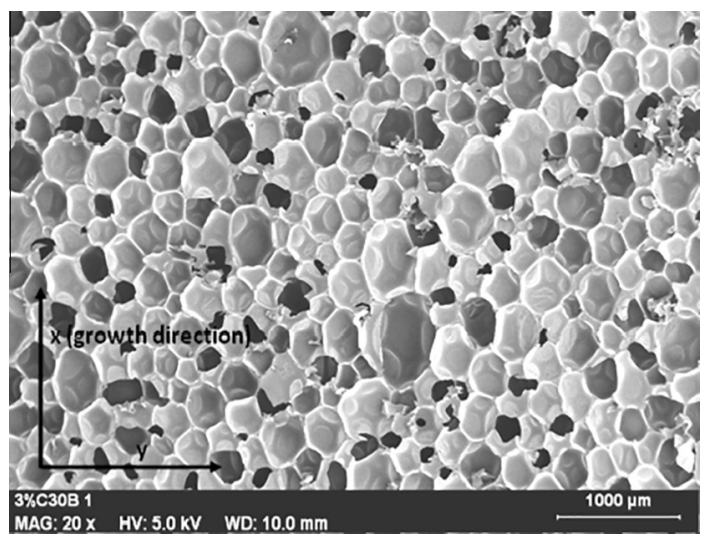

Fig. 1. SEM images: polyurethane foam containing $3 \%$ nanoclays.

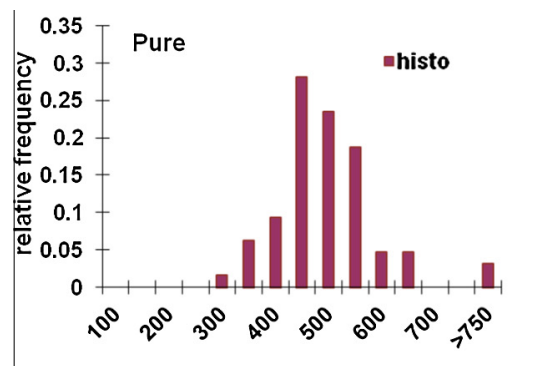

cell size $(\mu \mathrm{m})$

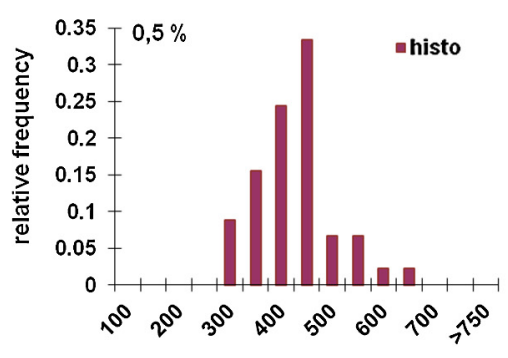

cell size $(\mu \mathrm{m})$

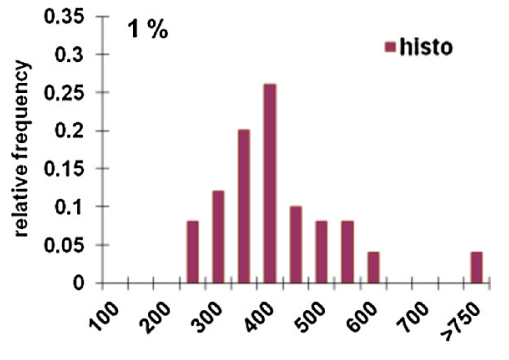

cell size $(\mu \mathrm{m})$
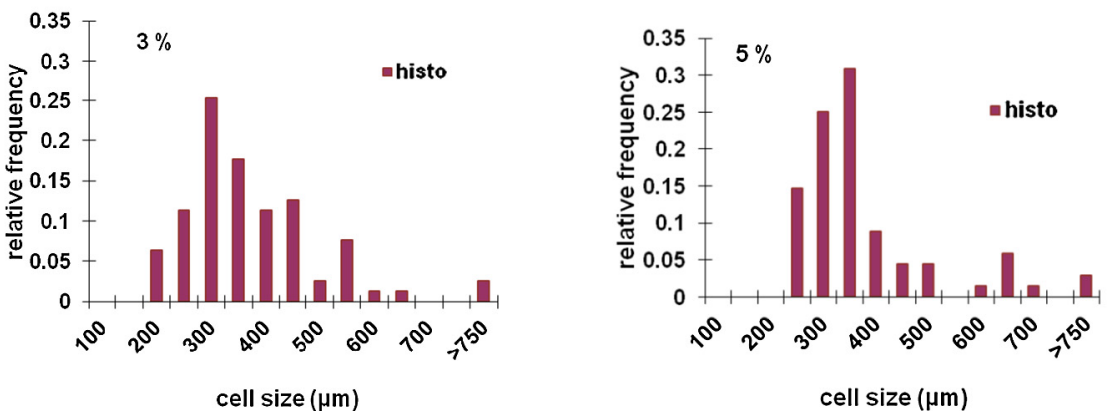

Fig. 2. Cell size distribution of all the analyzed materials.

The cell size distributions of Fig. 2 shows that the addition of nanoclays shifts the maximum of the cell size distribution to small values (cell size reduction) and that the width of the distribution is increased, as NSD values in Table 2 confirms.

Fig. 3 shows that the average cell size of the produced materials is reduced when the clays content is increased. The reduction is significant, from around $450 \mu \mathrm{m}$ for the pure foam to around $350 \mu \mathrm{m}$ for the material containing $5 \%$ clays. The reason for the observed cell size reduction is related with a nucleation effect of the nanoclays as a recent paper studying the same system has proved [32].

Table 2 collects the values of mass fraction in the struts $\left(\mathrm{f}_{\mathrm{s}}\right)$, anisotropy ratio (AR) and open cell content. The addition of clays increases $\mathrm{f}_{\mathrm{s}}$ for clays content above $3 \%$; this result could be related with the foam reaction kinetics. The presence of nanoclays could slow down the polymerization process [33] and/or speed up the blowing process as it is explained in more detail in the following section. Due to the longer times between blowing and gelling processes, capillary forces have more time to enhance drainage in the cell walls, increasing the fraction of material in the struts. In addition, Table 2 shows that the anisotropy ratio is reduced when clays are added. This behavior could be also related with the slowing down of the polymerization process and/or the increase in the speed of the blowing process that gives more time during growing for the reaccommodation of the bubbles produced. Another effect that could contribute to this modification of the anisotropy ratio is a viscosity increase due to the addition of nanoclays that could produces low elongation and stretching of foam cells in the rising direction [34]. 


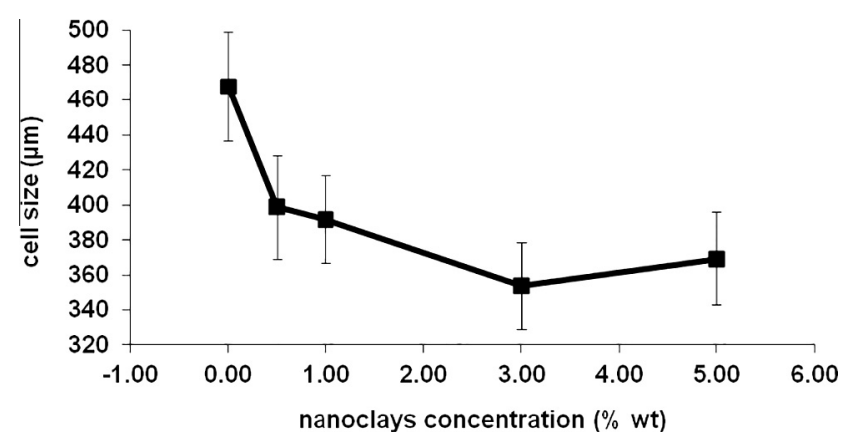

Fig. 3. Average cell size for the materials under study.

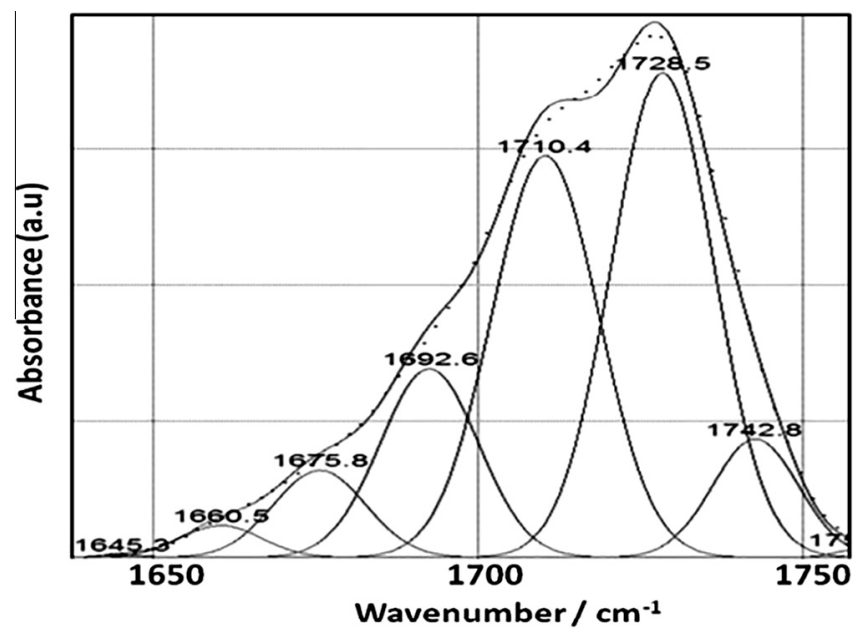

Fig. 4. Deconvolution (curve-fitting) in the amide I region for the spectrum of neat PU foam, taken after 16 min.

Finally, the open cell content of the samples shows a very small increase with the addition of nanoclays. This effect of nanoclays as cell opener is an expected behavior, considering previous studies [23,35].

\subsection{FTIR studies during the foaming process}

In order to characterize the blowing to gelling ratio, FTIR studies were carried out during the foaming process both for neat PU foam and for PU foam containing $5 \mathrm{wt} \%$ of nanoclays, which are the two extreme cases herein studied.

The overlapped absorptions in the amide I region were deconvoluted using Gaussians bands [36,37]. No baseline correction was used, and no restrictions were imposed on the deconvoluted band position, width or amplitude. In the amide I band (Fig. 4), the range from 1700 to $1740 \mathrm{~cm}^{-1}$ was assigned to free and hydrogen bonded urethanes ( $C=0$ stretching vibration [36-45]. The urea $C=0$ stretching vibration was assigned to free, disordered and ordered urea in the range $1640-1700 \mathrm{~cm}^{-1}$ $[33,37,39,45]$. Urethane linkages are directly related to the gelling reaction, while urea bonds are related to the blowing reaction. Therefore, the absorbances corresponding to the amide I band may be divided into two parts, related either to blowing or gelling processes. It should be noted that these are the main reactions occurring during foam formation.

Thus, for neat PU foam formation, the relative weight of the gelling and blowing reactions after 16 min (recording time, see Section 3.4) was: $78 \%$ of $C=0$ groups generated from gelling vs. $22 \%$ of $C=0$ groups produced from blowing. For the evolving foam containing $5 \%$ of nanoclays at the same time, this ratio was $72 \%$ (gelling) vs. $28 \%$ (blowing).

These observations strengthen the conclusions reached in the previous section dealing with foam characterization, where modifications in the cellular structure where associated to changes in the kinetics of chemical reactions involved in the foam formation. In this case, the polymerization process seems to be slowed down and/or the blowing reactions have been accelerated due to the presence of the clays, justifying the modifications found in the cellular structure.

\subsection{X-ray diffraction measurements}

A characteristic diffraction peak for a $2 \theta$ value close to $4.7^{\circ}$ is shown in the X-ray diffraction patterns of the polyol/clays and isocyanate/clay blends (Fig. 5). This value corresponds to an inter-lamellar average distance of $1.84 \mathrm{~nm}$, very close to the 


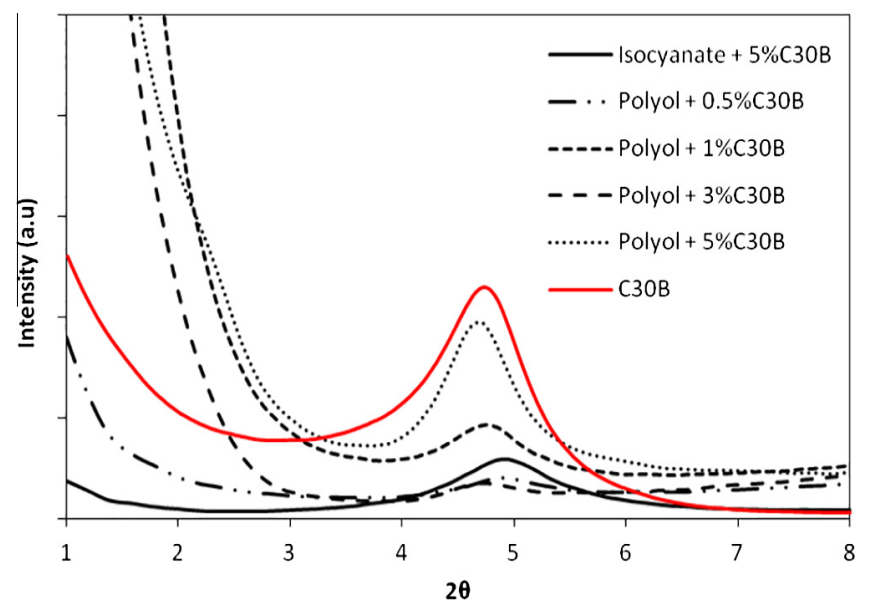

Fig. 5. Small angle X-ray diffraction patterns obtained for nanoclays-polyol and nanoclays-isocyanate suspensions after mixing with the pure nanoclays (C30B).

$1.85 \mathrm{~nm}$ data provided by the nanoclays supplier. As it can be observed in the figure this characteristics peak is located in the same position for the pure clays and for the blends. Therefore, a qualitative analysis of this data seems to indicate that the low shear mixing applied to disperse the nanoclays in the polyol was not enough to promote the intercalation of the nanoparticles.

A quantitative analysis of this data has been performed. The inter-lamellar space (d) was obtained using the Bragg equation and the crystallite size of nanoclays (D) was calculated using the Scherrer equation [46,47]:

$$
D=\frac{k \lambda}{\beta \cos \theta}
$$

where $\mathrm{k}$ is form factor (the value usually $=0.9), \lambda$ is the wavelength of incident wave $(\lambda=0.154 \mathrm{~nm}), \beta$ is the measured FWHM (full width at half maximum of the diffraction peak) and $\theta$ is the peak position. The number of the stacked individual silicate layers of each sample has been estimated dividing the crystallite size (D) by the inter-lamellar space (d) [46].

The calculated values of peak position (20), inter-lamellar space (d), full width at half maximum ( $\beta$ ), crystallite size (D) and the number of the stacked individual silicate layers for each blend are presented in Table 3. As it can be observed the inter-lamellar space does not significantly change in the blends. In addition, the crystal size increases when the clays are introduced into the polyol or isocyanate. Therefore, the results are in agreement with the previous qualitative observation; there is not intercalation of the clays during the low shear mixing in polyol or isocyanate.

The diffraction patters of the foamed materials containing nanoclays (Fig. 6) show two peaks, one at an angle between 4.3 and $4.8^{\circ}$ (similar to the one showed by the pure nanoclays) and another at lower angles (between 2.3 and $2.6^{\circ}$ ) that is not present in the as received clays. The appearance of the peak at lower angles seems to indicate that for some of the clay stacks there is a significant increase of the inter-lamellar distance that takes place during the foaming process (i.e. the foaming process induces the intercalation of some of the clay particles).

The calculated values of peak position (20), inter-lamellar space (d), full width at half maximum ( $\beta$ ), crystallite size (D) and the number of the stacked individual silicate layers obtained for the two characteristics peaks detected in the measurements are collected in Tables 4 and 5.

The crystal size of the peak at higher angles (corresponding to an inter-lamellar spacing of around $1.8-2.0 \mathrm{~nm}$ ) is smaller for the foams than for the pure clay. In addition, the crystal size for the peak located at lower angles, which corresponds to an inter-lamellar spacing of around 3.4-3.8 nm, decreases in size when higher amount of clays are added. The obtained results confirm that in some of the primary stacks of the clays and during the foaming process there is an intercalation of the polymer matrix leading to an increase of the inter-lamellar spacing. This effect is taking place in a part of the nanoclays stacks, i.e. is not taking place for all the clay stacks.

The results of this characterization are aligned with the conclusions reached in the previous section dealing with the analysis of the reaction kinetics, where chemical interactions between the nanoclays and the evolving mixture were proposed. These chemical interactions are helpful to promote an increase in the interlayer distance and an intercalated structure. This modification of the structure of the clays takes place during the foaming process.

\subsection{Experimental values of the thermal conductivity}

The evolution of thermal conductivity vs. time can be observed in Fig. 7, where the initial values have been measured 2 days after manufacturing, when a significant amount of the blowing agent $\left(\mathrm{CO}_{2}\right)$ is still present inside the cells. Other 
Table 3

Inter-lamellar spacing (d) and crystallite size (D) of the polyol/clay and isocyanate/clay suspensions.

\begin{tabular}{|c|c|c|c|c|c|}
\hline Samples & $2 \theta\left(^{\circ}\right)$ & $\mathrm{d}(\mathrm{nm})$ & FWHM $(\theta)$ & $\mathrm{D}(\mathrm{nm})$ & $\mathrm{D}(\mathrm{nm}) / \mathrm{d}(\mathrm{nm})$ \\
\hline С $30 \mathrm{~B}$ & 4.7 & 1.89 & 1.08 & 7.34 & 3.9 \\
\hline Polyol + 0.5\%С $30 \mathrm{~B}$ & 4.9 & 1.79 & 0.85 & 9.33 & 5.2 \\
\hline Polyol + 1\%С $30 \mathrm{~B}$ & 4.8 & 1.85 & 0.82 & 9.70 & 5.2 \\
\hline Polyol + 3\%С $30 \mathrm{~B}$ & 4.7 & 1.87 & 0.87 & 9.11 & 4.9 \\
\hline Polyol + 5\%C30B & 4.7 & 1.89 & 0.90 & 8.88 & 4.7 \\
\hline Isocyanate $+5 \% \mathrm{C} 30 \mathrm{~B}$ & 4.9 & 1.80 & 1.08 & 7.34 & 4.1 \\
\hline
\end{tabular}

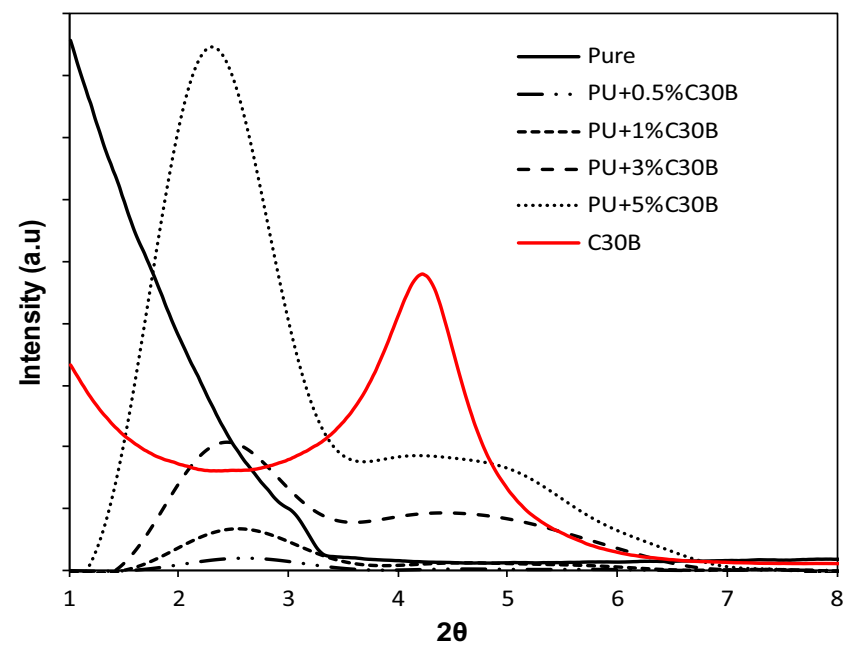

Fig. 6. Small angle X-ray diffraction patterns obtained for polyurethane nanocomposite foams containing different amounts of nanoclays and for pure nanoclays (C30B).

Table 4

Calculated values according to Bragg and Scherrer equations for the diffraction peak between 4.3 and $4.8^{\circ}$.

\begin{tabular}{|c|c|c|c|c|c|}
\hline Samples & $2 \theta$ & $\mathrm{d}(\mathrm{nm})$ & FWHM $(\theta)$ & $\mathrm{D}(\mathrm{nm})$ & $\mathrm{D}(\mathrm{nm}) / \mathrm{d}(\mathrm{nm})$ \\
\hline С $30 \mathrm{~B}$ & 4.66 & 1.89 & 1.08 & 7.34 & 3.9 \\
\hline $\mathrm{PU}+0.5 \% \mathrm{C} 30 \mathrm{~B}$ & 4.84 & 1.82 & 2.03 & 3.93 & 2.2 \\
\hline $\mathrm{PU}+1 \% \mathrm{C} 30 \mathrm{~B}$ & 4.77 & 1.85 & 2.08 & 3.83 & 2.1 \\
\hline $\mathrm{PU}+3 \% \mathrm{C} 30 \mathrm{~B}$ & 4.67 & 1.89 & 2.58 & 3.09 & 1.6 \\
\hline $\mathrm{PU}+5 \% \mathrm{C} 30 \mathrm{~B}$ & 4.32 & 2.04 & 2.69 & 2.95 & 1.4 \\
\hline
\end{tabular}

Table 5

Calculated values according to Bragg and Scherrer equations the diffraction peak between 2.3 and $2.6^{\circ}$.

\begin{tabular}{|c|c|c|c|c|c|}
\hline Samples & $2 \theta$ & $\mathrm{d}(\mathrm{nm})$ & FWHM $(\theta)$ & $\mathrm{D}(\mathrm{nm})$ & $\mathrm{D}(\mathrm{nm}) / \mathrm{d}(\mathrm{nm})$ \\
\hline $\mathrm{PU}+0.5 \% \mathrm{C} 30 \mathrm{~B}$ & 2.56 & 3.45 & 0.80 & 9.92 & 2.9 \\
\hline $\mathrm{PU}+1 \% \mathrm{C} 30 \mathrm{~B}$ & 2.56 & 3.45 & 1.11 & 7.18 & 2.1 \\
\hline $\mathrm{PU}+3 \% \mathrm{C} 30 \mathrm{~B}$ & 2.43 & 3.63 & 1.07 & 7.43 & 2.0 \\
\hline $\mathrm{PU}+5 \% \mathrm{C} 30 \mathrm{~B}$ & 2.30 & 3.83 & 1.14 & 6.97 & 1.8 \\
\hline
\end{tabular}

measurements were performed 12 days and 40 days after these first measurements. The increase in the thermal conductivity between day 2 and day 12 is due to the rapid diffusion of the foaming agent $\left(\mathrm{CO}_{2}\right.$; thermal conductivity at $20^{\circ} \mathrm{C}$ : $14.5 \mathrm{~mW} \mathrm{~m}^{-1} \mathrm{~K}^{-1}$ ) outwards the foam, and its substitution by atmospheric air, which has a higher thermal conductivity coefficient than $\mathrm{CO}_{2}$ (thermal conductivity at $20^{\circ} \mathrm{C}: 25.3 \mathrm{~mW} \mathrm{~m}^{-1} \mathrm{~K}^{-1}$ ) [48]. This rapid process is known and it is characteristics of water blown PU foams [48]. Nevertheless, Fig. 7(B) shows very small changes in the thermal conductivity from 12 to 40 after manufacturing. As explained below in the prediction of the thermal conductivity section, the gas phase term has a high weight in the final value of the thermal conductivity (ca. $71 \%$ of the final value), and thus small changes in the conductivity of this phase has a clear effect on the final value. 

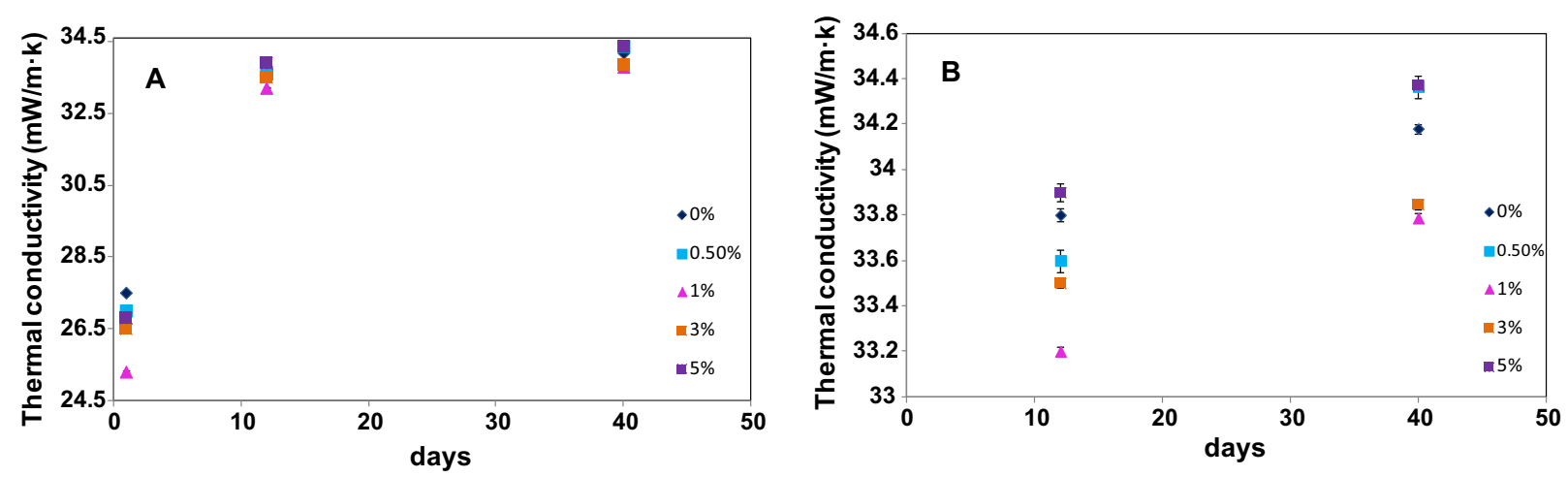

Fig. 7. Thermal conductivity evolution for different nanoclays concentration between day 2 and day 40 (A); and between day 12 and day 40 (B).

Fig. 8 displays the data of the thermal conductivity for foams with different nanoclays concentration 12 days after production. The values are in the range $33-34 \mathrm{~mW} / \mathrm{m} \mathrm{K}$ which are expected values for water blown rigid PU foams that after reaching the stationary state have air in the cells with a conductivity of $25.2 \mathrm{~mW} / \mathrm{m} \mathrm{K}$ at $20{ }^{\circ} \mathrm{C}$. The figure shows that the thermal conductivity decreases when the concentration of nanoclays increases, with a higher reduction for $1 \%$ nanoclays concentration. Different parameters control the final thermal conductivity of foams; one of them is the foam cell size $[22,24]$. Fig. 3 showed that cell size is reduced when clays are added. However, the same trend is not observed for the thermal conductivity vs. clays content curve. In this case, the thermal conductivity reaches a minimum for $1 \%$ of nanoclays, whereas higher concentrations lead to an increase of the conductivity with concomitant reduction of the cell size. This particular behavior might be originated by other contributions to the thermal conductivity, such as the thermal conductivity of the solid phase and/or the optical properties of the polymer matrix, which may be affected by the inclusion of high amounts of nanoclays, or by changes in the cellular structure at other levels, such as modifications of the mass fraction in the struts and/or the anisotropy ratio. These considerations will be analyzed, in the section dealing with theoretical modeling of thermal conductivity.

\subsection{Extinction coefficient: $K_{e, R}$ or $K$}

In practical applications, radiation travels only a short distance (mean free path) before being scattered or absorbed. The transferred energy depends only on the intermediate vicinity of the position being considered. This approximation is called diffusion approximation (in this process, the heat flux is proportional to the local gradient of the potential, in this case the black body emissive power $\left.\sigma T^{4}\right)$, and the radiative heat flux $q_{r}(x)$ can be expressed as follows [49]:

$$
q_{r}(x)=\frac{4}{3 K_{e, R}} \frac{\partial e_{b}}{\partial x}=\frac{-16 \sigma T^{3}}{3 K_{e, R}} \frac{\partial T}{\partial x}=-\lambda_{r} \frac{\partial T}{\partial x}
$$

where $\lambda_{r}$ is the radiative conductivity. Foams used in real applications are usually thick enough (several millimeters thick) to be considered optically thick; therefore, the radiative heat flux can be approximated by Rosseland equation [49] as follows:

$$
\lambda_{r}=\frac{16 n^{2} \sigma T^{3}}{3 K_{e, R}}
$$

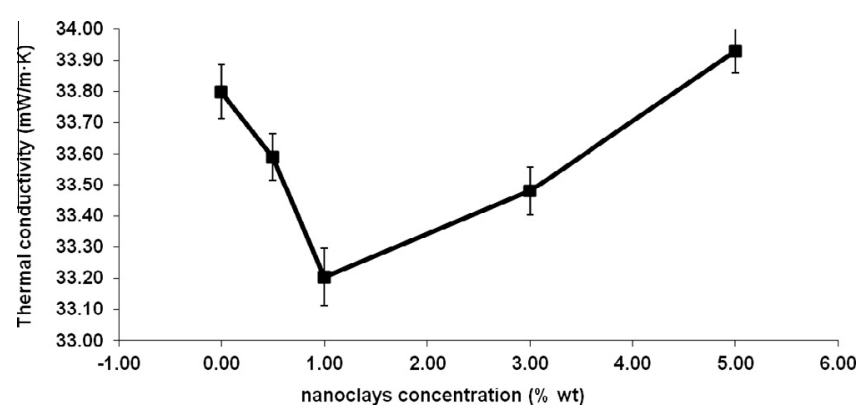

Fig. 8. Thermal conductivity as a function of nanoclays concentration. 
where $n$ is the effective refraction index and $K_{e, R}$ is the Rosseland mean extinction coefficient. For polymer foams, $n$ is close to one [50]. This approximation is valid in this study because the foams under analysis have a volume of gas (porosity) higher than $95 \%$. Under these conditions, $K_{e, R}$ can be obtained with the following equation [1]:

$$
\frac{1}{K_{e, R}}=\frac{\int_{0}^{\infty} \frac{1}{K_{e, \lambda}} \frac{\partial e_{b, \lambda}}{\partial T} d \lambda}{\int_{0}^{\infty} \frac{\partial e_{b, \lambda}}{\partial T} d \lambda}
$$

where $e_{b, \lambda}$ is the spectral black body emissive power and $\lambda$ is the wavelength. Therefore, the Rosseland mean extinction coefficient is an average value of $K_{e, \lambda}$ weighed by the local spectral energy flux. Once $K_{e, \lambda}$ is measured (see Section 3.4, Eqs. (2) and (3)), $K_{e, R}$ (or $K$ ) can obtained using Eq. (9). The Rosseland mean extinction coefficient $\left(K_{e, R}\right)$ and the mean values of the correlation coefficients due to the fitting of $K_{e, \lambda}$ versus $L$ are summarized in Table 6.

A preliminary analysis of these results shows that the extinction coefficient increases with the concentration of clays showing a maximum for a $3 \%$ concentration. A more detailed analysis of the data is included in the modeling and discussion section.

\subsection{Modeling}

\subsubsection{Modeling of the extinction coefficient}

Glicksman and coworkers [49,51-53] proposed an equation to predict the extinction coefficient of closed cell polyurethane foams. They considered pentagonal dodecahedral cells as a set of randomly oriented blackbody struts, and neglected scattering by the cell walls. The strut cross section was constant and occupied two- thirds of the area of an equilateral triangle formed at the vertices. The Glicksman extinction coefficient $\left(\mathrm{K}_{\mathrm{G}}\right)$ depends on the cell size $(\phi)$, foam density $\left(\rho_{f}\right)$ and solid polymer density $\left(\rho_{s}\right)$ :

$$
K_{G}=4.10 \frac{\sqrt{f_{S} \frac{\rho_{f}}{\rho_{s}}}}{\phi}
$$

where 4.10 is a constant related to the cell geometry and $f_{S}$ is the mass fraction in the struts.

Glicksman et al. also included the contribution of the cell walls $\left(\mathrm{K}_{\mathrm{H}} \mathrm{K}_{\mathrm{w}}\right.$, where $\mathrm{K}_{\mathrm{w}}$ is the extinction coefficient of the solid polymer). This contribution was then combined with that of the struts, to yield the overall extinction coefficient of a closed cell foam (Eqs. (11) and (12)):

$$
\begin{aligned}
& K_{G}=K_{\text {edges }}+K_{H} K_{W} \\
& K_{G}=4.10 \frac{\sqrt{f_{S} \frac{\rho_{f}}{\rho_{s}}}}{\phi}+\left(1-f_{S}\right) \frac{\rho_{f}}{\rho_{s}} K_{W}
\end{aligned}
$$

The cell wall term, which is valid for foams with thin cell walls $(\delta<30 \mu \mathrm{m})$, includes the hypothetical extinction coefficient for a uniform material occupying the entire volume of the foam and having the same attenuation as thin cell walls. As it has been mentioned above, $\mathrm{K}_{\mathrm{w}}$ is the extinction coefficient of the solid polymer, and an initial value for this property $\left(60,000 \mathrm{~m}^{-1}\right)$ was obtained from literature [49].

The results obtained when $\mathrm{K}$ is calculated using Eq. (11) together with the experimental extinction coefficients (Table 6) are shown in Fig. 9. Similar values are observed for the Glicksman model and the experimental results. In both cases K increases when the amount of clays are added, with an increase up to $3 \%$ nanoclays and then a reduction.

The average differences between the theoretical and experimental values are collected in Table 7 . These differences are not constant and present variations with the amount of nanoclays. In general terms, there is a clear change in the extinction coefficient behavior by the addition of nanoclays that cannot be explained only by a reduction of the cell size or by the modifications detected in the fraction of material in the struts (Table 2). The two components of Glicksman equation include information about the cellular structure and about the material that form the cell. If the Glicksman model is taken as valid, the difference with the experimental data could be associated to the change in $\mathrm{K}_{\mathrm{w}}$ due to the introduction of nanoclays. These data are showed in the last column of Table 7 indicating a clear increase of $\mathrm{K}_{\mathrm{w}} \mathrm{up}$ to $3 \%$ clays content and a decrease of $\mathrm{K}_{\mathrm{w}}$ for

Table 6

Experimental results for Rosseland extinction coefficient and correlation coefficient due to the fitting of $K_{e, \lambda}$ versus $L$.

\begin{tabular}{lll}
\hline Sample (nanoclays\%) & $\mathrm{K}_{\mathrm{e}, \mathrm{R}}\left(\mathrm{cm}^{-1}\right)$ & $\mathrm{R}^{2}$ \\
\hline 0 & $23.18 \pm 1.08$ & 0.988 \\
0.5 & $25.47 \pm 1.35$ & 0.996 \\
1 & $30.42 \pm 1.68$ & 0.995 \\
3 & $33.68 \pm 1.61$ & 0.985 \\
5 & $27.31 \pm 1.31$ & 0.990 \\
\hline
\end{tabular}




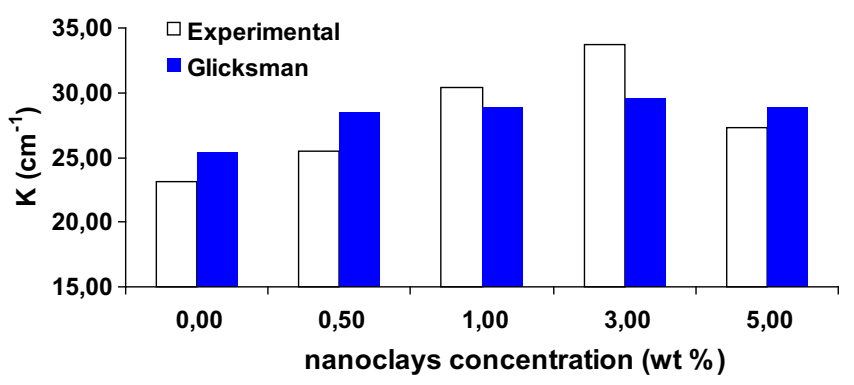

Fig. 9. Extinction coefficient: Glicksman model and experimental data.

Table 7

Extinction coefficient: experimental values, values predicted by the Glicksman model, difference between them and extinction coefficient of the solid material for a perfect fit between experimental data and Glicksman model.

\begin{tabular}{|c|c|c|c|c|}
\hline Sample (nanoclays con. wt\%) & $\mathrm{K}(\exp ).\left(\mathrm{cm}^{-1}\right)$ & K Gliks. $\left(\mathrm{cm}^{-1}\right)$ & Variation \% & $\mathrm{K}_{\omega}\left(\mathrm{m}^{-1}\right) \exp$. \\
\hline 0 & 23.18 & 25.40 & 9.56 & 46,266 \\
\hline 0.5 & 25.47 & 28.53 & 11.99 & 42,946 \\
\hline 1 & 30.42 & 28.91 & -4.94 & 68,945 \\
\hline 3 & 33.68 & 29.59 & -12.14 & 97,505 \\
\hline 5 & 27.31 & 28.93 & 5.95 & 46,488 \\
\hline
\end{tabular}

the material with the highest content of clays. Therefore, the experimental results suggest that clays have a significant effect on the optical properties of the solid polymer producing a modification of the extinction coefficient of the polymeric matrix.

\subsubsection{Prediction of thermal conductivity}

It is well known that the thermal conductivity of polymer foams is due to four mechanisms: conduction along the cell walls and the struts of the solid polymer $\left(\lambda^{s}\right)$, conduction through the gas phase $\left(\lambda^{g}\right)$, thermal radiation $\left(\lambda^{r}\right)$, and convection within the cells $\left(\lambda^{\mathrm{c}}\right)$. The total heat flow $\left(\lambda^{\mathrm{t}}\right)$ is a result of the four contributions and can be expressed by a superposition of each mechanism taken separately:

$$
\lambda^{t}=\lambda^{s}+\lambda^{g}+\lambda^{r}+\lambda^{c}
$$

The convective heat transfer is assumed to be negligible [49,53-57] because of the very small cell size of the foams under study $(350-500 \mu \mathrm{m})$. In a first approximation, it is possible to calculate the conductive terms of the gas and of the solid phases, and subtract them from the experimental value of the conductivity to obtain an experimental value of the thermal radiation term [55]. The expression of these terms is shown in Eqs. (14) and (15), where $V_{g}$ is the volume fraction of the gas phase $\left(1-\rho_{f} / \rho_{s}\right), V_{s}$ is the volume fraction of the solid phase $\left(\rho_{f} / \rho_{s}\right)$, AR is the anisotropy ratio, $\lambda_{\mathrm{g}}$ is the thermal conductivity of the air at a given temperature, and $\lambda_{s}$ is the thermal conductivity of solid polyurethane $\left(0.26 \mathrm{~W} \mathrm{~m}^{-1} \mathrm{~K}^{-1}\right)[53]$. The contribution to the thermal conductivity from the gas phase (Eq. (14)) depends on the nature of the gas. In our case, the gas is air at atmospheric pressure, which has a conductivity at $20{ }^{\circ} \mathrm{C}$ of $25.3 \mathrm{~mW} \mathrm{~m}{ }^{-1} \mathrm{~K}^{-1}$.

$$
\begin{aligned}
& \lambda^{g}=\lambda_{g} V_{g} \\
& \lambda^{s}=\lambda_{s} \frac{V_{s}}{3}\left(\left(f_{s} \sqrt{A R}\right)+2\left(1-f_{s}\right)(A R)^{1 / 4}\right)
\end{aligned}
$$

Using these values, it is possible to calculate the weight of each term on the thermal conductivity of the measured foams. In average, the conductivity of the gas phase is responsible of $c a$. $71 \%$ of the final conductivity of the foam. Solid conduction accounts for around $16 \%$ and radiation for around $13 \%$.

If we assume the validity of the Rosseland equation, the total conductivity $\left(\lambda^{t}\right)$ can be estimated by using the Eq. (16):

$$
\lambda^{t}=\lambda_{g} V_{g}+\lambda_{s} \frac{V_{s}}{3}\left(\left(f_{s} \sqrt{A R}\right)+2\left(1-f_{s}\right)(A R)^{1 / 4}\right)+\frac{16 \sigma T^{3}}{3 K_{e, R}}
$$

where $\sigma$ is the Stefan-Boltzmann constant, $T$ is the temperature and $K_{e, R}$ is the extinction coefficient. The value of $K_{e, R}$ can be the experimental one or the theoretical one calculated from the Glicksman expression (Eq. (12) and Table 7).

Fig. 10 shows the experimental and theoretical data of the total conductivity. A good correlation (differences lower than $7 \%$ ) is observed, with similar results for experimental extinction coefficient and Glicksman model. However, a different trend is observed, with a minimum for the experimental values at $1 \mathrm{wt} \%$ nanoclays concentration and at $3 \mathrm{wt} \%$ for both models. In addition, the predictions are close to the experimental values for the small clays contents, increasing these differences for higher clay concentrations. 

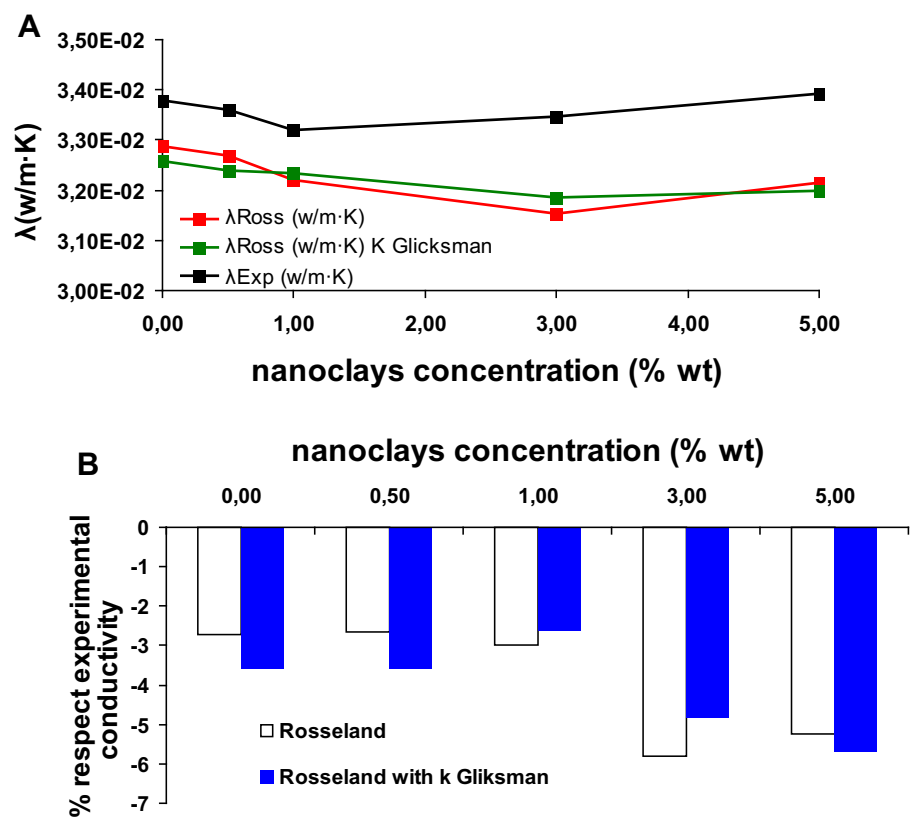

Fig. 10. Comparative of the experimental values and model prediction of the total thermal conductivity: (a) experimental values and (b) percentage of difference between experimental values and model predictions.

\section{Discussion}

In order to have a complete understanding of the measured changes in the thermal conductivity, an analysis of the different mechanisms involved in the final thermal conductivity value has been performed.

\subsection{Conduction through the gas phase}

This term is the most significant in the final value of the thermal conductivity, with a weight of $71 \%$ for the materials under study. For this reason, small changes in the thermal conductivity of the gas phase of the foam can produce significant changes in the total conductivity. This has been shown in Fig. 7, which displays the time evolution of the thermal conductivity. As explained previously, the gas present inside the cells changes from $\mathrm{CO}_{2}\left(14.5 \mathrm{~mW} \mathrm{~m}^{-1} \mathrm{~K}^{-1}\right)$ to atmospheric air (25.3 $\mathrm{mW} \mathrm{m}^{-1} \mathrm{~K}^{-1}$ ) due to the diffusion through the polymeric matrix. Some calculations can be performed with the employed model; assuming that conduction through the solid and radiation conductivity are time independent, therefore the contribution to thermal conductivity of the gas phase in the initial tests (2 days after production) can be calculated subtracting the solid phase and the radiation term contributions from the final value of the thermal conductivity. These calculations show that the value of the gas conductivity is between 18 and $20 \mathrm{~mW} \mathrm{~m} \mathrm{~K}^{-1}$ for the thermal conductivity initial value. This implies that a mixture of $\mathrm{CO}_{2}$ and air is present in the cells, and its thermal conductivity could be calculated in a first approximation by the Wassiljewa equation [58]:

$$
\lambda_{m}=\sum_{i=1}^{n} \frac{y_{i} \lambda_{i}}{\sum_{j=1}^{n} y_{j} A_{i j}}
$$

where $\lambda_{m}$ is the thermal conductivity of the mixture, $\lambda_{i}$ is the thermal conductivity of pure component $i, y_{i}$ and $y_{j}$ are the molar fractions of components $i$ and $j$ and $A_{i j}$ is a function of the binary system that is equal to 1 .

This equation allows deducing that approximately a $40 \%$ of $\mathrm{CO}_{2}$ present in the cells has been substituted by air 2 days after the production of the foam.

This is due to different aspects. The first one is the high diffusion coefficient of $\mathrm{CO}_{2}$. In addition another mechanism which could contribute to this very quick diffusion effect is related to the differences of pressure between the gas contained in the cells and the external atmosphere. The evolving foam is expanding against ambient pressure until the polymerization reaction finishes and then the foam is brought to room temperature. Thus the pressure inside the cells growths depending on the amount of gas produced and the final temperature reached during the foaming process. When the foam finally cools down (at cell volume approximately constant), the pressure inside the cells would drop below ambient pressure and the pressure in the cells could be different depending on the temperatures reached during foaming. 
Similar calculations can be made for measurements performed at higher times (12 and 40 days), which lead to obtain $100 \%$ of air concentration, thus confirming that after 12 days the composition of the gas in the cells reached a stationary value. Other factor affecting the conduction through the gas term is the open cell content, but it can be discarded as the main source of differences between material, because this structural characteristic (Table 2) presents negligible changes for the cellular nanocomposites. Therefore, once the conductivity reaches a constant value the effect of nanoclays on the heat transfer by conduction through the gas phase should be negligible.

\subsection{Radiation term}

This contribution experiments substantial changes due to the presence of nanoclays. Considering Eq. (8), this term is deeply related with changes in the extinction coefficient (higher extinction coefficient implies lower conductivity). In turn, accepting Glicksman model, extinction coefficient is also related with solid polymer density, cell size, mass fraction in struts and extinction coefficient of the polymeric matrix. The comparison between experimental and theoretical results suggest that the trends observed can only be explained if an increase of the extinction coefficient of the solid matrix by the presence of the clays is taking place. Therefore, the nanoparticles are acting as IR-blockers when they are added in small proportions. Table 7 shows an estimation of the extinction coefficient of the polymeric matrix, $\mathrm{K}_{\omega}$. It is clearly observed that $\mathrm{K}_{\omega}$ increases as nanoclays concentration grows with a maximum for $3 \%$ of nanoclays, then, a reduction appears. This behavior has been previously observed in nanocomposites; as nanoparticles concentration increases producing nanocomposites with a god dispersion is more difficult and beyond a critical particle concentration there is a drop in the measured properties [59].

\subsection{Conduction through the solid}

An increase in the concentration of clays in the foam could increase the thermal conductivity of the polymeric matrix $\lambda_{s}$. Part of the differences between experimental and theoretical data observed in Fig. 10 could be due to this variation. As previously mentioned a different trend between experimental data and a models prediction is observed: models present a minimum for thermal conductivity of $3 \mathrm{wt} \%$, whereas for experimental data the minimum is reached at $1 \mathrm{wt} \%$. In addition, the difference between experimental data and theoretical predictions increase with the clays concentration. So these differences might be explained considering a variation of the conduction through the solid phase. Using Eq. (16), it is possible to estimate the values of $\lambda_{s}$ that would result in a perfect fit between experimental data and predictions. Fig. 11 shows how the calculated values depend on the concentration of nanoclays. For the materials with a low concentration the variations of $\lambda_{s}$ are very small. In addition, a clear increase of $\lambda_{s}$ with the nanoclays concentration is observed for 3 and $5 \mathrm{wt} \%$.

The increase of the solid thermal conductivity for higher concentration of nanoclays could be as a consequence of the creation of a percolation network for the nanoclays. The percolation threshold of this network might be between 1 and $3 \%$, so its effect should be detected from $3 \mathrm{wt} \%$ and should increase for higher concentrations. Rheological characterization could help to clarify this subject [50,60], showing the percolation concentration for these materials.

The decrease of the solid contribution for low concentration of clays predicted by the models (Fig. 11) might be related to the possibility of changes in the cell geometry when adding nanoclays. In a previous study using tomography [28], it was demonstrated that an alteration of the average number of cell neighbors (cell coordination number) takes place when nanoclays are present. Eq. (15) is based on the assumption that foam microstructure is formed by pentagonal dodecahedra cells. If this were not the case, this equation should be modified introducing a parameter $\mathrm{C}\left(\mathrm{f}_{\mathrm{s}}\right)$ as follows:

$$
\lambda^{s}=C\left(f_{s}\right) \lambda_{s} \frac{V_{s}}{3}\left(\left(f_{s} \sqrt{A R}\right)+2\left(1-f_{s}\right)(A R)^{1 / 4}\right)
$$

In which $\mathrm{C}<1$ and its value could depend on cell geometry and "architecture" (i.e. fraction of mass in the struts).

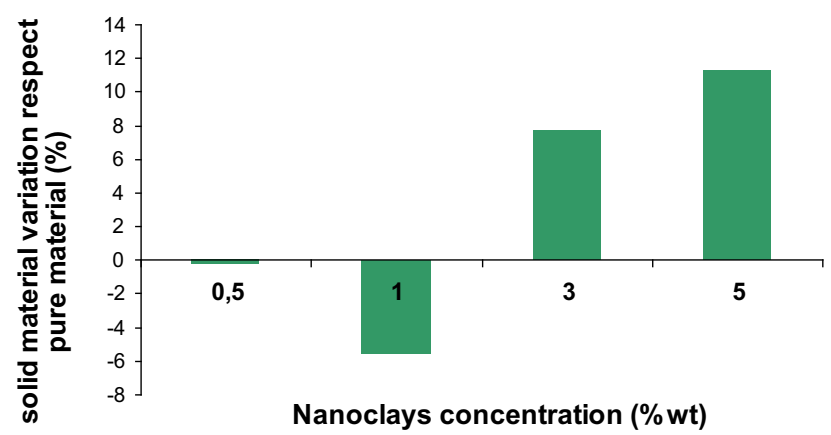

Fig. 11. Solid polymer conductivity variation (in percentage) with respect to that of the pure material to obtain a perfect fit between experimental data and models predictions. 
The average cell coordination values found is $c a$. 12 neighbors, that is, the coordination number expected for a monodisperse foam with cells modeled as dodecahedrons. When nanoclays are present in the foam, a significant population of cells showed either low or high coordination numbers (although cells kept their average dodecahedral coordination). This allows concluding that the dodecahedron coordination might coexist with different polyhedrons, with both a high and low number of faces.

Therefore, two effects are possibly affecting the heat transfer trough the solid phase in these foams: the modification of the cell microstructure (cell shape), and the formation of a percolating network of the particles. Taking into account the data of Fig. 11, the modification of the cellular architecture seems to predominate for lower amounts of nanoclays, whereas the network formation is prevailing for higher concentrations.

As a summary of this discussion, we can conclude that the changes produced in the thermal conductivity are due to morphological changes in the cellular structure (as the cell size, mass fraction on struts, cell shape, etc.), but also to changes in the thermal and optical properties of the polymeric matrix, effect that modify the conduction through the solid phase and the heat conduction by radiation.

\section{Conclusions}

Cellular nanocomposites based on rigid PU and montmorillonite have been produced and characterized.

X-ray diffraction and FTIR studies point to some type of chemical interaction between the nanoclays and the evolving foam. This interaction plays an important role in the foam formation, what leads to a slight unbalance of the gelling and blowing reactions when compared to that occurring for neat foam formation. In addition, this interaction promotes the intercalation of the clay particles during foaming.

The measurements of thermal conductivity carried out have allowed concluding that the inclusion of nanoclays gives rise to a reduction of the thermal conductivity, with a higher reduction for $1 \mathrm{wt} \%$ of nanoclays content. Concentrations higher than $1 \mathrm{wt} \%$ do not produce higher reductions of the thermal conductivity.

Other characteristics, as foam cell size, fraction of material in the struts and extinction coefficient are also altered due to the inclusion of nanoclays. Nevertheless, the addition of nanoclays in polyurethane foams produces changes beyond the morphological structure of the foams. In particular, the results of this research have indicated that there are modifications of the extinction coefficient and of the conductivity of the polymeric matrix due to the clays addition.

For this reason, finding out an optimal concentration of nanoclays to produce foams with the lowest thermal conductivity is crucial. A correct understanding of the different alterations produced by the additives is essential not only to determine the ideal nanoclay concentration in the material, but also to extrapolate the results to other polyurethane systems with different nanoadditives.

\section{Acknowledgements}

We would like to acknowledge to Mr. Vela and Mr. Ferrer, from BASF Española S.L., for supplying the PU formulation employed in this research. The authors are grateful to the Spanish Ministry of Science and Education which supported this work with a FPU Grant Ref-AP-2008-03602 given to Mr. Estravís. In addition, Financial assistance from the Spanish Ministry of Science and Innovation, FEDER program (MAT 2012 - 34901 and MAT2015-69234-R), the Junta de Castile and Leon (VA035U13) and the EU Commission (FP7 program, EC project NanCore number 214148) is acknowledged.

\section{References}

[1] H.R.N. Jones, Radiation Heat Transfer, Oxford Science, Oxford, 2000.

[2] A. Cunningham, D. Sparrow, J. Cellul. Polym. 5 (1986) 327-342.

[3] D. Baillis, J.F. Sacadura, J. Quant. Spectrosc. Radiat. Transfer 67 (2000) 327-363.

[4] C.J. Tseng, M. Yamaguchi, T. Ohmori, Cryogenics 37 (1997) 305-312.

[5] J.W. Wu, W.F. Sung, H.S. Chu, Int. J. Heat Mass Transfer 42 (1999) 2211-2217.

[6] L.J. Lee, C. Zeng, X. Cao, X. Han, J. Shen, G. Xu, Polymer nanocomposite foams, Compos. Sci. Technol. 65 (2005) $2344-2363$.

[7] S. Pavlidou, C.D. Papaspyrides, Progress Pol. Sci. 33 (2008) 1119-1198.

[8] R. Verdejo, C. Saiz-Arroyo, J. Carretero-Gonzalez, F. Barroso-Bujans, M.A. Rodriguez-Perez, M.A. Lopez-Manchado, Eur. Pol. J. 44 (2008) $2790-2797$.

[9] J.I. Velasco, M. Ardanuy, V. Realinho, M. Antunes, A.I. Fernández, J.I. González-Peña, M.A. Rodríguez-Pérez, J.A. de Saja, J. Appl. Pol. Sci. 102 (2006) 12131223.

[10] S.G. Miller, J.L. Bauer, M.J. Maryanski, P.J. Heimann, J.P. Barlow, J.M. Gosau, R.E. Allred, Comp. Sci. Technol. 70 (7) (2010) $1120-1125$.

[11] G. Siqueira, J. Bras, A. Dufresne, Biomacromolecules 10 (2) (2008) 425-432.

[12] P.C. Ma, N.A. Siddiqui, G. Marom, J.K. Kim, Compos. A Appl. Sci. Manuf. 41 (10) (2010) 1345-1367.

[13] Y. Kojima, A. Usuki, M. Kawasumi, A. Okada, Y. Fukushima, T. Kurauchi, O. Kamigaito, J. Mater. Res. 8 (1993) 1185.

[14] M.C. Saha, Md E. Kabir, S. Jeelani, Mater. Sci. Eng. A 479 (2008) 213-222.

[15] M. Modesti, A. Lorenzetti, S. Besco, D. Hrelja, S. Semenzato, R. Bertani, R.A. Michelin, Polym. Degrad. Stab. 93 (2008) $2166-2171$.

[16] X. Cao, L.J. Lee, T. Widya, C. Macosko, Polymer 46 (2005) 775-783.

[17] F.J. Galindo-Rosales, P. Moldenaers, J. Vermant, Macromol. Mater. Eng. 296 (2011) 331-340.

[18] M. Joulazadeha, A.H. Navarchian, Polym. Adv. Technol. 22 (2011) 2022-2031.

[19] Md E. Kabir, M.C. Saha, S. Jeelani, Mater. Sci. Eng. A 459 (2007) 111-116.

[20] H. Mahfuz, V.K. Rangari, M.S. Islam, S. Jeelani, Compos. A Appl. Sci. Manuf. 35 (2004) 453-460.

[21] T. Widya, C.W. Macosko, J. Macromol. Sci., Part B: Phys. 44 (6) (2005) 897-908.

[22] M. Modesti, A. Lorenzetti, S. Besco, Polym. Eng. Sci. 47 (2007) 1351-1358. 
[23] G. Harikrishnan, T.U. Patro, D.V. Khakhar, Ind. Eng. Chem. Res. 45 (21) (2006) 7126-7134.

[24] M.A. Rodríguez-Pérez, J.I. González-Peña, N. Witten, J.A. de Saja, Cell. Pol. 21 (3) (2002) 165-194.

[25] Cloisite ${ }^{\circledR}$ 30B technical data sheet. Southern Clay Products.

[26] L. Betega de Paiva, A.R. Morales, F.R. Valenzuela Díaz, Appl. Clay Sci. 42 (2008) 8-24.

[27] J. Pinto, E. Solórzano, M.A. Rodriguez-Perez, J.A. de Saja, J. Cell. Plast. 49 (6) (2013) 554-574.

[28] S. Pardo-Alonso, E. Solórzano, L. Brabant, P. Vanderniepen, M. Dierick, L. Van Hoorebeke, Eur. Pol. J. 49 (2013) 999-1006.

[29] K. Liang, S.Q. Shi, J. Appl. Pol. Sci. 119 (3) (2011).

[30] Ł. Piszczyk, M. Strankowski, M. Danowska, J.T. Haponiuk, M. Gazda, Eur. Pol. J. 48 (2012) 1726-1733.

[31] M. Thirumal, D. Khastgir, N.K. Singha, B.S. Manjunath, Y.P. Naik, J. Appl. Pol. Sci. 108 (3) (2008) $1810-1817$.

[32] S. Pardo-Alonso, E. Solórzano, S. Estravís, M.A. Rodríguez-Perez, J.A. de Saja, Soft Matter 8 (2012) 11262-11270.

[33] M.M. Bernal, M.A. Lopez-Manchado, R. Vedejo, Macromol. Chem. Phys. 212 (2011) 971-979.

[34] H. Bahrambeygi, A. Rabbi, K. Nasouri, A.M. Shoushtari, M.R. Babaei, Adv. Polym. Technol. 32 (2012) E545-E555.

[35] R. Gu, M.M. Sain, J. Pol. Environ. 21 (2013) 30-38.

[36] D.P. Queiroz, D.P. Queiroz, M.N.d. Pinho, C. Dias, Macromolecules 36 (2003) 4195-4200.

[37] A. Marcos-Fernández, A.E. Lozano, L. González, A. Rodríguez, Macromolecules 30 (1997) 3584-3592.

[38] M.J. Elwell, A.J. Ryan, H.J.M. Grünbauer, H.C.V. Lieshout, Macromolecules 29 (1996) 2960-2968.

[39] M.J. Elwell, A.J. Ryan, Polymer 37 (1996) 1353-1361.

[40] A.L. Daniel-da-Silva, J.C.M. Bordado, J.M. Martín-Martínez, J. Appl. Polym. Sci. 107 (2008) 700-709.

[41] M.M. Coleman, M. Sobkowiak, G.J. Pehlert, P.C. Painter, T. Iqba, Macromol. Chem. Phys. 198 (1997) $117-134$.

[42] L. Ning, W. De-Ning, Y. Sheng-Kang, Macromolecules 30 (1997) 4405-4409.

[43] V.V. Zharkov, A.G. Strikovsky, T.E. Verteletskaya, Polymer 34 (1993) 935-941.

[44] A.G. Strikovsky, V.V. Zharkov, Polymer 34 (1993) 3397-3401.

[45] W. Li, A.J. Ryan, Macromolecules 35 (2002) 6306-6312.

[46] S.S. Ray, K. Yamada, M. Okamoto, K. Ueda, Polymer 44 (2003) 857-866.

[47] V.A. Dritis, C. Tchoubar, X-ray Diffraction by Disordered Lamellar Structures, Springer-Verlag, New York, 1990 (Chapter 1).

[48] C.J. Hoogendoorn, in: N. C Hilyard, A. Cunningham (Eds.), Low Density Cellular Plastics: Physical Basis of Behaviour, Chapman \& Hall, London, 1994 (Chapter 6)

[49] L.R. Glicksman, in: N.C. Hilyard, A. Cunningham (Eds.), Low Density Cellular Plastics: Physical Basis of Behaviour, Chapman \& Hall, London, 1994 (Chapter 5).

[50] R. Krishnamoorti, K. Yurekli, Curr. Opin. Colloid Interface Sci. 6 (2001) 464-470.

[51] L.R. Glicksman, M. Torpey, in: Proceedings of Polyurethane World Congress, Aachen, Germany, 1987.

[52] L.R. Glicksman, A. Marge, J.D. Moreno, Dev. Radiat. Heat Transfer 203 (1992) 45-54.

[53] L.R. Glicksman, Polymers 10 (1991) 276-293.

[54] J. Kuhn, H.P. Ebert, Int. J. Heat Mass Transfer 35 (1992) 1795-1801.

[55] M.A. Rodríguez-Pérez, O. Alonso, J. Souto, J.A. De Saja, Polym. Test 16 (1997) 287-298.

[56] O.A. Almanza, M.A. Rodríguez-Pérez, J.A. De Saja, J. Polym. Sci., Part B: Polym. Phys. 38 (2000) 993-1004.

[57] J.A. Martínez-Díez, M.A. Rodríguez-Pérez, J.A. de Saja, L.O. Arcos y Rábago, O.A. Almanza, J. Cell. Plast. 37 (2001) $21-42$.

[58] R.C. Read, J.M. Prausnitz, T.K. Sherwood, The Properties of Gases and Liquids, third ed., McGraw-Hill, NY, 1977.

[59] Y. Zheng, Y. Zheng, R. Ning, Mater. Lett. 57 (19) (2003) 2940-2944.

[60] I. Novák, I. Krupa, I. Chodák, J. Mater. Sci. Lett. 21 (13) (2002) 1039-1041. 